\title{
Prevalence and treatment of post partum urinary incontinence
}

\author{
Siv Mørkved, MSc, $\mathrm{PT}^{1,3}$, and Kari Bø, PhD, PT, $\mathrm{PE}^{2}$ \\ 1. Sør-Trøndelag College, School of Health Education, Nursing and Social Work, Physiotherapy Department, \\ Ranheimsveien 10, 7005 Trondheim, Norway \\ 2. Norwegian Centre for Physiotherapy Research, Box 7009 Majorstua, 0306 Oslo, Norway \\ 3. Correspondence to: Siv Mørkved, College of Sør-Trøndelag, Physiotherapy Department, Ranheimsveien 10, 7005 Trondheim, Norway \\ Telephone +47 $73828200 \quad$ Telefax +4773828201 E-mail siv.morkved@ahs.hist.no
}

The article is based on a lecture given by the first author at the workshop on "Pelvic Floor and Physiotherapy for Urinary Incontinence" at the International Continence Society's Annual Meeting in Athens, Greece, 1996.

\begin{abstract}
SUMMARY
Childbirth is often considered the main etiological factor in the development of female urinary incontinence (UI). For that reason women in the western countries have been encouraged to engage in post partum pelvic floor muscle (PFM) exercise in order to strengthen the pelvic floor. However, the effect of post partum PFM exercise has been sparsely documented. The aim of this article is to review and discuss literature related to prevalence of post partum UI and effect of post partum PFM exercise in the treatment of UI. The reported prevalence of UI post partum varies from $0.7 \%$ to $44 \%$. The variation may be explained by different definitions of UI used in the questionnaires and that the registration of incontinence was done at different intervals after delivery. A few studies have tried to evaluate the effect of post natal PFM exercise. Some have evaluated PFM strength, others the frequency of UI. PFM strength is difficult to measure and the reliability and validity of the methods used is open to question. Another flaw in some of the previous studies is the training protocol applied to improve PFM strength. Mørkved and Bø tried to take into account the above mentioned methodological considerations, in a study aiming to evaluate the effect of post partum PFM exercise. The results demonstrate that post partum PFM exercise is effective in strengthening the PFM and in the treatment of UI. However, success of PFM exercise is dependent upon both the training frequency and intensity. This requires a closer follow up of the post partum women, than the written information that usually serves this purpose at the present time.
\end{abstract}

Key words: physiotherapy, pelvic floor muscles, urinary incontinence, post partum exercise, prevalence

\section{INTRODUCTION}

Female urinary incontinence (UI) is often considered a problem primarily occuring after childbirth. However, Bø et al. (1) and Jolleys (2) have found a prevalence of $31 \%$ in young nulliparous women. The prevalence of UI is twice as high in women as in men (3). Prevalence studies of female stress urinary incontinence show a variation from $8 \%(4)$ to $52 \%(5)$. The variation may be explained by different populations investigated and the use of different definitions of incontinence in the questionnaires. Stress urinary incontinence (SUI) is the type of incontinence most frequently affecting women $(6,7)$. The definition of SUI is involuntary loss of urine occuring during physical exertion (coughing, laughing, exercise) (8). Genuine stress incontinence (GSI) is defined as the involuntary loss of urine which occurs when, in the absence of a detrusor contraction, the intravesical pressure exceeds the maximum uretral pressure (8). Enhørning (9) explained the mechanism behind GSI as descent of the bladder and the urethra during an abrupt rise in intra-abdominal pressure. Normally the ligaments and the pelvic floor muscles (PFM) keep the bladder and the urethra within the intraabdominal cavity. If these supporting tissues are too elastic the urethra may descend. The hypothesis is that hypermobility is caused by weak connective tissue within the pubourethral ligaments (10). Such movement of bladder and urethra has been visualized in incontinent women by ultrasonography $(11,12)$. For a 
short period of time the bladder pressure is higher than the urethral pressure, and leakage may occur.

\section{Etiology}

Age, menopause, connective tissue disorders and overweight is mentioned as etiological factors in the development of SUI (13). However, childbirth is often considered the main etiological factor. SUI after childbirth has been explained as a consequence of peripheral nerve damage (14-16). Snooks et al. (17) followed patients for 5 years and found persistent and impaired pudendal nerve damage. Rupture of muscle fibers and connective tissue and overstretching of supporting ligaments are other risk factors $(18,19)$.

\section{Postpartum PFM exercise in the treatment of urinary incontinence}

As early as 1948 the american gynecologist Arnold Kegel emphasized the value of PFM exercise in restoring function after childbirth (20). Since that time women in the western countries have been encouraged to engage in post partum PFM exercise in order to strengthen the pelvic floor (21).

Specialists in women's health care have focused on the role of the PFM in maintaining adequate pelvic support; for example maintaining the position and function of the bladder, uterus and rectum (22). DeLancey (23), Constantinou (24) and Koelbl et al. (11) have all emphazised the important role of the pelvic floor in maintenance of urinary continence. The theory behind PFM exercise in the treatment of SUI is that a strong and fast reflex contraction will clamp the urethra, thereby increasing urethral pressure during an abrupt increase in intra-abdominal pressure. DeLancey (23) has suggested that during PFM contraction the urethra will be pressed against the pubic symphysis, producing a mechanical pressure rise. There is some evidence that the PFM "reflex contraction" is an anticipatory control mechanism (24).

Pre- and postnatal care are fields in which physiotherapists have been engaged both in preventive care and in treatment, in hospitals as well as in the community health service. Instructing women to conduct PFM exercise to rehabilitate the pelvic floor after delivery is one important part of postnatal care. However, the effect of post partum PFM exercise has been sparsely documented.

The aim of this article is to review and discuss literature concerning prevalence of post partum UI and effect of post partum PFM exercise in the treatment of UI.

\section{METHODS}

The article is based on papers written in English compiled from computerized searches on Medline from 1983 to 1996, manual searches for articles found in references from this litterature, and a manual search of the proceedings of the International Continence Society.

\section{RESULTS}

\section{Prevalence}

A higher prevalence of SUI has been demonstrated in parous than in nulliparous women (25-27). Prevalence of urinary incontinence post partum varies from $0.7 \%$ (28) to $44 \%$ (29). The variation may be explained by different definitions of incontinence used in the questionnaires and that the registration of incontinence was done at different intervals after delivery. The lowest prevalence is reported in studies where incontinence is defined according to the International Continence Society's definition: "a condition in which involuntary loss of urine is a social or hygienic problem and is objectively demonstrated" (8).

Both Stanton et al. (30), Allen \& Warell (15) and Sampselle et al. (31) found that the prevalence of SUI rose during pregnancy and then declined after childbirth, indicating that the increased pressure from the growing uterus on the bladder may temporarily cause leakage during pregnancy. When the increased weight disappear after delivery, incontinence may disappear in some women. However, Allen and Warell (15) demonstrated a higher prevalence after delivery than before gestation.

Nygaard et al. (25) and Jolleys (2) found a higher prevalence with higher parity and Beck \& Hsu (32) reported that the incontinence was progressively worse with successive pregnancies. On the other hand, Thomas et al. (33) could not demonstrate any differences within parity ranges of 1 to 3 . However, the prevalence was increased in women having 4 or more children. No longitudinal studies have been conducted.

Iosif (34) concluded that onset of incontinence is more often found during the first pregnancy than during subsequent pregnancies. Demonstrating a prevalence of $9 \%$ in women delivering with cesarean section, Iosif et al. (35) concluded that the pregnancy itself and hereditary factors may predispose more than parturition trauma in some women.

Wilson et al. (36) showed that the mode of delivery, parity, pre-pregnancy BMI and antenatal PFM exercise are significantly related to the prevalence of urinary incontinence three months after delivery. They found that UI appeared to be a very common problem, affecting just over $34 \%$ of the women sampled.

\section{Effect of post partum PFM exercise}

In two retrospective studies Spence (37) and Bredsel et al. (38) found the strongest PFM in women performing PFM exercise during pregnancy and after delivery.

Gordon and Lounge (39) measured vaginal pressure in 70 women 12-14 months after delivery. Significant difference between three groups was 
found. The group of women performing PFM exercise at the hospital and general physical activity afterwards, showed higher vaginal pressure measurements than women performing PFM at hospital and no following training. The lowest vaginal pressure was found in women not exercising at all.

In a prospective study Sleep and Grant (29) used a questionnaire to evaluate prevalence of UI in 1800 women. During a 4 week period, one group had performed intensive PFM exercise and another group had performed the customary PFM training program. The prevalence of UI was similar in both groups 3 months post partum.

The training protocols were not standardized in any of the above mentioned studies.

Comparing two training groups and a control group, Dougherty et al. (40) found higher improvement in PFM strength in the training groups, than in the control group $(\mathrm{N}=15)$. Vaginal palpation and vaginal pressure readings was conducted before (6-17 weeks p.p.) and after (12-32 weeks p.p.) a 6 week training period. However, the difference was not statistically significant. The sample size was small and the standard deviation in vaginal pressure was large.

In a prospective study of 83 women, Jonasson et al. (41) used vaginal cones to measure PFM strength in two postnatal groups before and after a training period. The training program was carried out by the women at home for 12 weeks, starting 8 weeks after spontaneous uneventful delivery. A group performing PFM exercise with vaginal cones improved significantly more than a group performing without. However, according to Hahn (42) and Bø (43) the validity of PFM strength measurements by vaginal cones, can be questioned. Neither Dougherty nor Jonasson registered UI.

Dumolin et al. (44) assessed PFM strength and reduction of UI in eight women, both before and after attending a physical therapy program. The program consisted of pelvic floor neuromuscular electrostimulation combined with exercises. A $92 \%$ increase in vaginal pressure and a significant reduction of UI were measured in the population. A major limitation of the study was the lack of a control group.

PFM strength is difficult to measure and the reliability and validity of the methods used is open to question. Bø et al. (45) concluded that an inward movement of the perineum must be visually observable during PFM contraction, in order that the vaginal pressure measurement be considered valid. This criterion has not been applied in previous studies.

Another flaw in some of the previous studies is the training protocol applied to improve PFM strength. The general recommendation for strength training is 3 to 4 sets of 8-12 high resistant, close to maximum, slow velocity contractions three times per week (46). In some rehabilitation situations, however, maximum contraction - or overload - is not possible and more frequent training sessions need to be utilized and are often more desirable. Restoring function after child- birth might be considered such a rehabilitation situation. The results of strength training are specific to the type of contractions being trained. This means that the training situation should reflect the function in which the effect is wanted. The PFM are regular skeletal muscles, consisting of both slow and fast twitch fibers, which also reflects the function of the PFM: Namely to keep the bladder and the urethra within the intraabdominal cavity $(11,12)$ and also to support the bladder and urethra during increased abdominal pressure (24).

Aiming to study increase in PFM strength after postpartum PFM exercise, Mørkved and Bø tried to take into account the above mentioned methodological considerations (47). The study group consisted of 66 matched pairs of women. Matching criteria were age, parity and type of delivery. Eight weeks after delivery all women were individually instructed in pelvic floor anatomy and how to contract the PFM correctly. The ability to contract the PFM was controlled by vaginal palpation and observation of the movement of a vaginal balloon catheter during PFM contraction. No observable synergistic contraction of other muscles was accepted. Feedback - knowledge of results and performance - was provided by the physiotherapist.

The training group (TG) followed a specially designed PFM exercise course, based on strength training principles in exercise physiology: The women were training with a physiotherapist in groups of 5-10 participants for 45 minutes once a week for a period of 8 weeks. The physiotherapist encouraged the participants to contract the PFM as hard as possible and to hold each contraction for 6-8 seconds. At the end of each contraction - following Bø et al. (49) - 3-4 fast contractions were added. In addition they were asked to perform 8 to 12 maximum PFM contractions twice a day at home. Frequency of exercise was recorded in a training diary. Participant motivation was strongly emphasized by the physiotherapist.

The control group (CG) received, from the hospital, the customary written postnatal instructions, which included encouragement to perform daily contractions of the PFM. They were not discouraged from performing PFM exercise on their own.

PFM strength was measured in both groups the 8th week and the 16th week after delivery. The results demonstrate a significantly greater improvement in PFM strength measured by vaginal pressure, in the TG compared to the CG. The results also indicate that the success of post partum PFM exercise is dependent upon the training frequency and intensity. Thorough instruction and measurement of improvement might be important key factors in motivation and adherence to training. Written or verbal instructions with no clinical assessment seems to have little effect.

Mørkved and Bø also evaluated the effect of postpartum PFM exercise in prevention and treatment of UI. Preliminary results demonstrate a significantly greater reduction in prevalence of UI in a training group compared to a control group (49). 


\section{CONCLUSION}

Prevalence of UI is higher among parous than nulliparous women and vaginal delivery is considered a main factor in the etiology of UI. Nevertheless, further work needs to be done enquiring about the onset and duration of incontinence.

The effect of post partum PFM exercise in prevention and treatment of UI has been sparsely documented. However, a recent Norwegian study shows that post partum PFM exercise is effective in strengthening the PFM and in treatment of UI. Success of PFM exercise is dependent upon both the training frequency and intensity. This requires a closer follow up of the post partum women, than the written information which usually serves this purpose at the present time.

It is essential that future services for women after childbirth should be organized according to results from controlled clinical trials.

\section{REFERENCES}

1. Bø K, Mæhlum S, Oseid S, Larsen S. Prevalence of stress urinary incontinence among physically active and sedentary female students. Scand J Sports Sci 1989; 11 (3): 113-116.

2. Jolleys JV. Reported prevalence of uinary incontinence among women in a general practice. $\mathrm{Br} \mathrm{Med} J 1988$; 296: 1300-1302.

3. National Institutes of Health. Urinary incontinence in adults. Washington, DC: Medical Applications of Research. National Institutes of Health 1988: 7: 1-11.

4. Iosif S, Henriksson L, Ulmsten U. The frequency of disorders of the lower urinary tract, urinary incontinence in particular, as evaluated by a questionnaire survey in a gynaecological health control population. Acta Obstet Gynecol 1981; 60: 71-76.

5. Nemir A, Middleton RP. Stress incontinence in young nulliparous women. Am J Obstet Gynecol 1954; 68: 1166-1168.

6. Fall M, Frankenberg S, Frisen M, Larson B, Petren M. 456.000 svenskar kan ha urininkontinens. Endast var fjärde söker hjälp för besvären. Läkartidningen 1985: 82: 2054-2056.

7. Hørding U, Pederssen KH, Sidenius K, Hedegaard L. Urinary incontinence in 45-year-old women. Scand J Urol Nephrol 1986: 20: 183-186.

8. Abrams P, Blavias JG, Stanton SL, Andersen JT. The standardisation of terminology of lower urinary tract function. Scand J Urol Nephrol 1988: Suppl 114: 5-19.

9. Enhørning G. Simultaneous recording of intravesical and intra-urethral pressure. Acta Chir Scand 1961: 276 (Suppl): 1-48.

10. Ulmsten U, Ekman G, Giertz G, Malmstrøm A. Different biochemical composition of connective tissue in continent and stress incontinent women. Acta Obstet Gynecol Scand 1987; 66: 455-457.

11. Koelbl H, Bernascheck G, Wolf G. A comparative study of perineal ultrasound scanning and urethrocystography in patients with genuine stress incontinence. Arch Gynecol Obstet 1988; 244: 39-45.

12. Hanzal E, Berger E, Koelbl H. Levator ani muscle morphology and recurrent genuine stress incontinence. Obstet Gynecol 1993; 81: 426-429.

13. Bø K. Stress urinary incontinence, physical activity and pelvic floor muscle strength training. Scand J Med Sci Sports 1992; 2: 197-206.

14. Snooks SJ, Setchell M, Swash M, Henry MM. Injury to innervation of pelvic floor sphincter musculature in childbirth. Lancet 1984 (Sept 8): 546-550.

15. Allen RE, Warell D. The role of pregnancy and childbirth in partial denervation of the pelvic floor. Neurourol Urodyn 1987; 6: 183-184.

16. Allen RE, Hosker GL, Smith ARB, Warell DW. Pelvic floor damage and childbirth: a neurophysiological study. Br J Obstet Gynaecol 1990; 97: 770-779.

17. Snooks SJ, Swash M, Mathers SE, Henry MM. Effect of vaginal delivery on the pelvic floor: a five year follow up. Br J Surg 1990; 77: 1358-1360.

18. Sayer TR, Dixon JS, Hosker GL, Warell DW. A study of periurethral connective tissue in women with stress incontinence of urine. Neurourol Urodyn 1990; 9: 319-320.

19. Landon CR, Crofts CE, Smith ARB, Trowbridge EA. Mechanical properties of facia during pregnancy: a possible factor in the development of stress incontinence of urine. Contemp Rev Obstet Gynaecol 1990; 2: 40-46.

20. Kegel AH. Progressive resistance exercise in the functional restoration of the perineal muscles. Am J Obstet Gynecol 1948; 56: 238-249.

21. Polden M, Mantle J. Physiotherapy in Obstetrics and Gynaecology. Butterworth \& Heinemann, 1992.

22. Nichols DH, Milley PS. Functional pelvic anatomy: the soft tissue supports and spaces of the female pelvic organs. Reprod Med 1978; 2: 21-37. 
23. DeLancey JOL. Anatomy and mechanics of structures around the vesical neck: how vesical neck position might affect its closure. Neurourol Urodyn 1988; 7 (3): 161-162.

24. Constantinou CE, Govan DE. Contribution and timing of transmitted and generated pressure components in the female urethra. In: Female Incontinence. New York: Allan R. Liss, 1981: 113-120.

25. Nygaard I, DeLancey JOL, Arnsdorf L, Murphy E. Exercise and incontinence. Obstet Gynecol 1990: 75: 848851.

26. Thomas TM, Plymath KT, Blannin J, Meade TW. Prevalence of urinary incontinence. Br Med J 1980: 281: 1243-1245.

27. Sommer P, Bauer T, Nielsen KK, Kristensen ES, Hermann GG, Steven K, Nordling J. Voiding patterns and prevalence of incontinence in women. A questionnaire survey. Br J Urol 1990: 66: 12-15.

28. Viktrup L, Lose G, Rolf M, Barfoed K. The frequency of urinary symptoms during pregnancy and puerperium in the primipara. Int Urogynecol J 1993; 4: 27-30.

29. Sleep J, Grant A. Pelvic floor exercises in postnatal care. Midwifery 1987; 3: 158-164.

30. Stanton SL, Kerr-Wilson R, Harris VG. The incidence of urological symptoms in normal pregnancy. $B r J$ Obstet Gynaecol 1980; 87: 897-900.

31. Sampselle CM, DeLancey JOL, Ashton-Miller J. Neurourol Urodyn 1996; 15 (4): 329-330.

32. Beck KP, Hsu N. Pregnancy, childbirth, and the menopause related to the development of stress incontinence. Am J Obstet Gynecol 1965; 91: 820-823.

33. Thomas TM, Plymath KT, Blannin J, Meade TW. Prevalence of urinary incontinence. Br Med J 1980; 281: 1243-1245.

34. Iosif S. Stress incontinence during pregnancy and puerperium. Int J Gynecol Obstet 1981; 19: 13-20.

35. Iosif S, Ingemarsson I. Prevalence of stress incontinence among women delivered by elective cesarean section. Int J Gynecol Obstet 1983; 20: 87-89.

36. Wilson PD, Herbison RM, Herbison GP. Obstetric practice and the prevalence of urinary incontinence three months after delivery. Br J Obstet Gynaecol 1996; 103: 154-161.

37. Spence M. Postnatal survey. Aust J Physiother 1978; 3: 151-160.

38. Brendsel C, Peterson G, Mehl LE. Routine epistiotomi and pelvic symptomatology. Women \& Health 1980; 5 (4): $49-61$.

39. Gordon H, Lounge M. Perineal muscle function after childbirth. Lancet 1985; ii: 123-125.

40. Dougherty M, Bishop KR, Abrams RM, Batich CD, Gimotty PA. The effect of exercise on the circumvaginal muscles in postpartum women. J Nurse Midwifery 1989; 34 (1): 8-14.

41. Jonasson A, Larsson B, Pschera H. Testing and training of the pelvic floor muscles after childbirth. Acta Obstet Gynecol Scand 1989; 68: 301-304.

42. Hahn I. Pelvic floor training for genuine stress incontinence. Evaluation and long term results. Doctoral Thesis, Departement of Surgery and Departement of Obstetrics and Gynecology, University of Gothenburg, Gothenburg, Sweden, 1993.

43. Bø K. Vaginal weight cones. Theoretical framework, effect on pelvic floor muscle strength and female stress urinary incontinence. Acta Obstet Gynecol Scand 1995; 74: 87-92.

44. Dumoulin C, Seaborne DE, Quirion-DeGirardi C, Sullivan SJ. Pelvic-floor rehabilitation, Part 2. Phys Ther 1995; 75 (12): 1075-81.

45. Bø K, Hagen RH, Kvarstein B, Larsen S. Pelvic floor muscle exercise for the treatment of female stress urinary incontinence II. Validity of vaginal pressure measurements of pelvic floor muscle strength. The necessity of supplementary methods for control of correct contraction. Neurourol Urodyn 1990; 9: 479-87.

46. DiNubile NA. Strength training. Clin Sports Med 1991; 10 (1): 33-63.

47. Mørkved S, Bø K. The effect of post-natal exercises to strengthen the pelvic floor muscles. Acta Obstet Gynecol Scand 1996; 76: 382-385.

48. Bø K, Hagen RH, Kvarstein B, Jørgensen J, Larsen S. Pelvic floor muscle exercise for the treatment of stress urinary incontinence III. Effects on two different degrees of pelvic floor muscle exercises. Nerourol Urodyn 1990; 9: 489-502.

49. Mørkved S, Bø K. The effect of post-natal exercises in the treatment of urinary incontinence. Neurourol Urodyn 1996; 15: 412-413. 